\title{
Hydatid cyst of ovary: an unusual site
}

\author{
Neha A. Goyal ${ }^{1}$, Ritu R. Vaidya ${ }^{2}$, Sarah H. Zaidi ${ }^{1 *}$, Manisha R. Gandhewar ${ }^{1}$ \\ ${ }^{1}$ Department of Obstetric and gynecology, Esic pgimsr, Andheri East, Mumbai, India \\ ${ }^{2}$ Department of Surgery, Esic PGIMSR, Andheri East, Mumbai, India
}

Received: 08 September 2015

Revised: 14 September 2015

Accepted: 29 October 2015

\author{
*Correspondence: \\ Dr. Sarah H. Zaidi, \\ E-mail: sarahzaidi1812@gmail.com
}

Copyright: ( $\odot$ the author(s), publisher and licensee Medip Academy. This is an open-access article distributed under the terms of the Creative Commons Attribution Non-Commercial License, which permits unrestricted non-commercial use, distribution, and reproduction in any medium, provided the original work is properly cited.

\begin{abstract}
Discovering a hydatid cyst in pelvic region, especially as primary localization, is a rare event; as a matter of fact according to data provided by literature the incidence is between 0.2 and $2.25 \%$. The ovarian involvement is often secondary to a cyst's dissemination localized in a different site. When possible the optimal treatment is represented by radical laparotomic cystectomy. We report a case of an old postmenopausal woman presented with intermittent dull aching pain with 16 weeks cystic pelvic mass which mimicked the ovarian malignancy even after imaging techniques. We treated the case with laprotomic cystectomy
\end{abstract}

Keywords: Ovarian hydatid, Albendazole, Cytectomy

\section{INTRODUCTION}

Hydatid disease is an important public health problem influenced by socioeconomic status \& population migration. ${ }^{1}$ Human echinococcosis is cause by larval stage of echinococcus granulosus and echinococcus multilocularis. ${ }^{2}$ The life cycle involves two hosts definitive carnivore host (dogs and cats) and intermediate herbivore host ( sheep and goat). Humans are infected as an accidental intermediate hosts. Following primary infection hydatid cyst can inhabit at any anatomic site from head to toe. Here we are presenting the case of secondary ovarian hydatid cyst.

\section{CASE REPORT}

55 years old multiparous, postmenopausal lady presented with intermittent dull aching lower abdomen pain since 45 months. On examination mild hepatomegaly and 16 weeks size cystic pelvic mass was present. On ultrasonography a $8.8 \times 5.7 \times 4.5 \mathrm{~cm}$ hepatic parenchymal cyst along with a $12.4 \times 12.7 \times 4.5 \mathrm{~cm}$ thin walled left ovarian cyst was seen. These findings were confirmed on CECT (Figure 1). Tumor markers (AFP, CEA) were normal however CA 125 was mildly raised $(52 \mathrm{u} / \mathrm{ml})$. Based on imaging findings immunological studies were done, Echinococcus IgG values were raised 5.4 (normal < $0.9)$. In retrospective patient gave history of prior surgery for hydatid cyst of liver.

Patient was explored through midline laparotomy. Omental adhesions with pelvic mass were present (Figure 2 ). Adhesiolysis was done, a thick walled cystic ovarian mass $(12 \times 11 \mathrm{~cm})$ was seen, cystic mass was unroofed after tasking adequate precautions to prevent spillage with mops soaked in hypertonic saline placed all around the mass. Cyst contents were aspirated and then cyst was opened. Daughter cyst were seen and removed. Left ovary with entire cyst was removed and sent for histopathological examination. A calcified cyst was also present in right lobe of liver. Cyst contents were aspirated and marsupialisation of hepatic cyst was done. 
Histopathology confirmed diagnosis of hepatic and ovarian hydatid cyst.

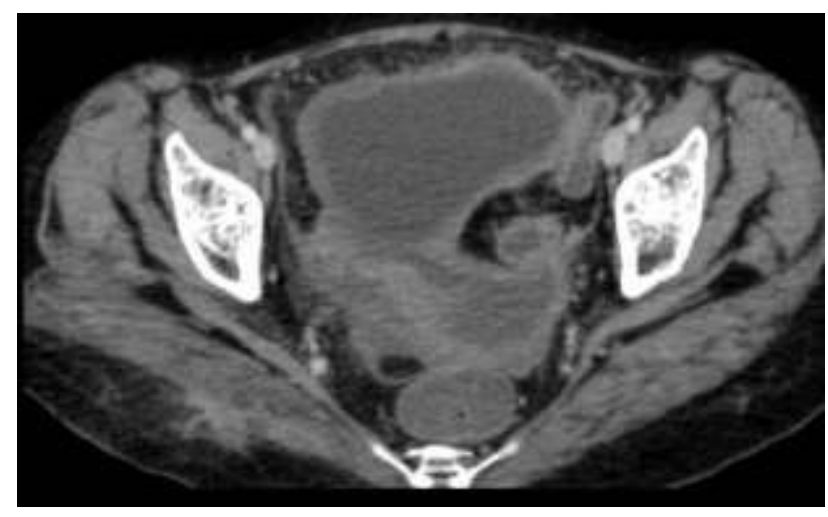

Figure 1 (a): CECT scan image.

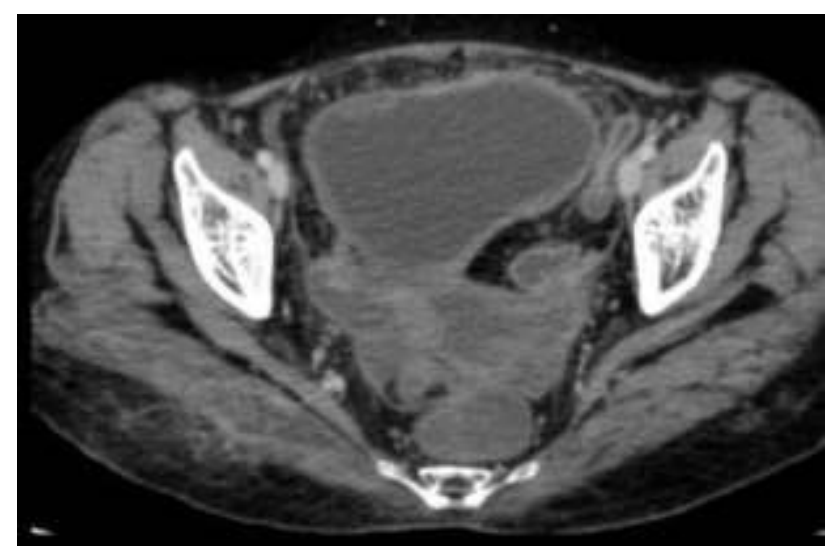

Figure 1 (b): CECT scan image.

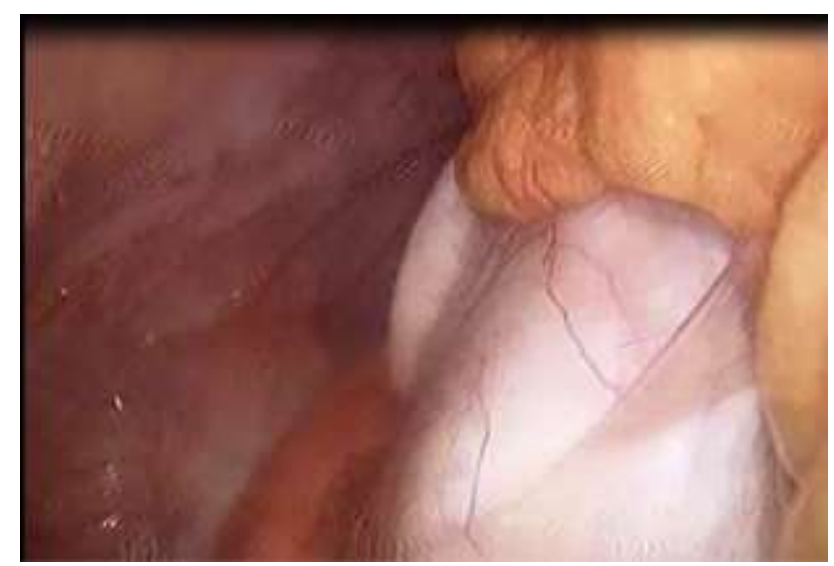

Figure 2: Intraoperative finding of omental adhesions with pelvic mass.

\section{DISCUSSION}

Hydatid cyst most frequently occur in the liver (63\%) followed by the lungs $(25 \%)$, muscles $(5 \%)$ and bones $(5 \%)$. Other uncommon sites reported are kidney, brain and spleen. Primary hydatid cyst of pelvis is relatively rare, ${ }^{3}$ with reported incidence $0.2-2.25 \%{ }^{4}$ In $80 \%$ cases ovary is affected organ., ${ }^{5,6}$ Cases of primary ovarian hydatid cysts are reported, but commonly the affection is secondary to dissemination from another site. ${ }^{7,9}$

In our case also the presentation is most probably due to prior spontaneous or iatrogenic rupture at the time of previous laparotomy. Diagnosis was based on patient's clinical history, biochemical and serological profiles and histopathological diagnosis.

Presentation of pelvic echinococcosis is usually nonspecific and can include abdominal pain, menstruation irregularities, infertility and urinary disturbance. Ovarian echinococcosis can mimick either polycystic disease or malignancy. The diagnostic challenge is due to the nonspecific symptomatology, along with atypical ultrasonographic finding of a solid ovarian mass. Daughter cyst may resemble septal structures and mimic complicated ovarian cyst or even ovarian malignancy.

Serological test to differentiate hydatid cyst from nonparasitic cysts or abscess has sensitivity varying from $64 \%$ to $87 \%$. Histopathological examination is required for final confirmatory diagnosis. A high grade of suspicion or a preoperative diagnosis of echinococcus cyst makes it possible to avoid an intraoperative iatrogenic rupture, and when available, to administer previously an albendazole-based therapy in order to reduce the risk of dissemination that can lead to recurrences. In our case ultra-sound (US) and CT scan associated with a positive clinical history of a previous hepatic echinococcal cyst raised the preoperative suspicion for hydatid disease, helping us to be better prepared to take the necessary precautions to prevent spillage.

Surgical removal of cyst is the mainstay of treatment. Cyst rupture should be prevented. Chemotherapy with benzidimizole has also been used with some success to sterilize the cyst, reducing chances of anaphylaxis and recurrences. Less radical measures like PAIR (puncture, aspiration, injection and reaspiration) have been described for those who are not surgical candidates.

\section{CONCLUSIONS}

Ovarian hydatid cyst is a rare entity. This disease constitutes a serious problem of public health in the endemic countries. In order to interrupt the cycle of transmission of hydatid cyst, public health measures should be implemented to eradicate the disease by the removal of infected animals. High index of suspicion and appropriate intraoperative measures must be taken to prevent spillage and thereby recurrences.

\section{Funding: No funding sources \\ Conflict of interest: None declared \\ Ethical approval: Not Required}




\section{REFERENCES}

1. Yuksel M, Demirpolat G, Sever A, Bakaris S, Bulbuloglu E, Elmas N. Hydatid disease involving some rare locations in the body: A pictorial essay. Korean J Radiol. 2007;8(6):531-40.

2. Saidi F. Treatment of echinococcal cyst. In: Nyhus LM, Beker JR, Fischer JE, eds. Mastery of Surgery. 3rd ed. Philadelphia, Little Brown and Company. 1997: 1035-1042.

3. Baba A, Chaieb A, Khairi H, Keskes J. Profil epidemiologique de l'hydatidose pelvienne à propos de 15 cas. J Gynecol Obstet Bio Report. 1991;20:657-60.

4. Rahman MS, Rahman J, Lysikiewcz A. Obstetric \& Gynaecological presentations of hydatid disease. Br J Obstet Gynaecol. 1982; 89:665-70.

5. Dede S, Dede H, Caliskan E, Demir B. Recurrent pelvic hydatid cyst obstructing labor, with a concomitant hepatic primary. A case report. J Reprod Med. 2002;47(2):164-6.
6. Pekindil G, Tenekeci N. Solid-appearing pelvic hydatic cyst: transabdominal and transvaginal sonographic diagnosis. Ultrasound Obstet Gynecol. 1997;9(4):289-91.

7. Aysun A, Petek BK, Mehmet AY, Omer Yalcin. Huge solitary primary pelvic hydatid cyst presenting as an ovarian malignancy: case report. J TurkishGerman Gynecol Assoc. 2009;10:181-3.

8. Echenique Elizondo MM, Amondarain Arratibel JA. Muscular hydatid disease. J Am Coll Surg. 2003;197(1):162.

9. Arif SH, Shams UB, Wani NA, Zargar SA, Wani M.A, Tabassum R. Albendazole as an adjuvant to the standard surgical management of hydatid cyst liver. Int J Surg. 2008;6(6):448-51.

Cite this article as: Goyal NA, Vaidya RR, Zaidi SH, Gandhewar MR. Hydatid cyst of ovary. Hydatid cyst of ovary: an unusual site. Int J Reprod Contracept Obstet Gynecol 2015;4:2053-5. 